\title{
Fatty Acid Composition in Cultured Amphiascoides neglectus (Copepoda: Harpacticoida)
}

\author{
Zaleha Kassim, Amir Safwan Hamzah, Hidayah Atirah Hashim, and Hazwani Hanim Hasnan \\ Kulliyyah of Science, International Islamic University Malaysia, Kuantan, Pahang, Malaysia \\ Email: drzack@iium.edu.my
}

\begin{abstract}
This study investigates the effect of salinity on the fatty acid profile of a harpacticoid copepod Amphiascoides neglectus exposed to constant laboratory lighting and temperature $\left(25-26^{\circ} \mathrm{C}\right)$ at $\mathrm{pH} 7$ for 40 days. The results were compared with those cultured in the common open hatchery environment which is almost the same as in the natural ecosystem. Different fatty acid levels were determined using Gas Chromatography and Mass Spectrometry (GC-MS). Results showed that there were no significant differences $(\mathrm{p}>0.05)$ in fatty acid content for both 20ppt and 30ppt treatment but the percentage of EPA was higher in 20ppt. Harpacticoid copepods in the hatchery showed significantly $(\mathrm{p}<0.05)$ more fatty acids in 30ppt than 20ppt. EPA was also higher in harpacticoids cultured under 30ppt. Manipulation of salinity and temperature in combination of light factor for copepod rearing system could improve the deposition of fatty acids in their body.
\end{abstract}

Keywords: Harpacticoid culture, fatty acid, EPA, culture environment

\section{$1 \quad$ Introduction}

Harpacticoid copepods fit the criteria of being a model animal by having a short generation time, being flexible in diet and tolerant towards a wide range of environmental factors [1][2][3]. They also have a small adult size [4][5], as well as being readily available by having their population widespread across the globe and capable of producing large amounts of offspring in a short time. They were reported to be the major attraction for small fishes to enter the intertidal zone during high tide [6].They are highly adapted in many coastal ecosystem [7] thus become the most available diet for fish larvae [8].

In the field of aquaculture, temperate harpacticoid copepod is well recognized as important live feed for newly hatched larval of fishes and shrimps in hatchery. Cutts [9] confirmed on the superiority of harpacticoid over artemia as early diet for larvae due to the ability to synthesize EFAs. Tisbe biminiensis was reported to be able to bio-convert fatty acid C18:0 into chains with 20 unsaturated carbons [10].

The concentration of fatty acids was reported as dependent to the environmental factors in the water body. A temperate harpacticoid, Platychelipus littoris showed a high degree depletion in fatty acid storage when exposed to elevated temperatures [11]. Low temperature (below $15^{\circ} \mathrm{C}$ ) on the other hand could trigger stress in lipogenesis process thus retards growth in copepods [12]. Theoretically, increase in temperature and warm condition would cause the salinity of the seawater to be increased as the evapotranspiration process would occur. Therefore, the fatty acid composition in copepods would have changed as well as an adaptation to the changing environment [13]. The different in diet was also noted to affect the fatty acid composition [14]. Nonetheless, some copepod species could have the capability to adjust their PUFA depending on the environmental variation unless the sudden environmental changes occurred [15].

Mimicking the natural environment in investigating the role of environmental changes towards the fatty acid content in tropical harpacticoid copepods could improve our understanding on the survival of copepods in tropic. The consistent warmer condition and more daylight could somehow play a role in the accumulation of fatty acid in the tissue. The aim of this research is to determine the fatty acid composition in harpacticoid copepod Amphiascoides neglectus cultured under several conditions in laboratory and hatchery.

\section{$2 \quad$ Materials and Methods}




\subsection{Stock Culture of Harpacticoid}

Stocks of benthic harpacticoid copepods for this study were collected from a copepod culture that was previously maintained in the hatchery in our research station. Harpacticoid copepods were separated from other organisms by using standard laboratory sieves with a mesh size of 62 microns. Samples were acclimated in a stock culture with autoclaved sea water of $30 \mathrm{ppt}$ salinity at $\mathrm{pH} 7$ for a period of one month, and was fed daily with $1 \mathrm{~mL}$ of baker's yeast $\left(0.02 \mathrm{~g} \mathrm{~L}^{-1}\right)[16]$.

Stock samples were also acclimated to ambient temperature, which in this project is defined as temperature ranging between $25^{\circ} \mathrm{C}$ to $26^{\circ} \mathrm{C}$. This was made by maintaining the air-conditioner at 25$26^{\circ} \mathrm{C}$ during the experiment period.

\subsection{Experiment 1: Effect of Salinity onto Harpacticoids under a Laboratory Condition}

Several copepod individuals were transferred from the stock culture to serially arranged glass beakers of $100 \mathrm{ml}$ each. Each beaker contained a number of 100 individual copepods. Water quality parameters were maintained under ambient temperature at different salinity of 5,20, and 30 ppt in replicates of three. Hand-held refractometer (ATAGO) was used to measure the desired salinity. The experiment was then repeated under different temperatures of $20^{\circ} \mathrm{C}$ and $28^{\circ} \mathrm{C}$. All cultures were maintained at $\mathrm{pH} 7$. Each of the glass beakers was covered with aluminium foil in order to prevent contamination. The cultures were done entirely under laboratory conditions, and were exposed to artificial light sources for 24 hours per day.

Temperature for each culture was maintained using air-conditioned rooms at $20^{\circ} \mathrm{C}$ and $28^{\circ} \mathrm{C}$, while cultures for ambient temperature are placed in an air-conditioned room operating between $25^{\circ} \mathrm{C}$ to $26^{\circ} \mathrm{C}$. Each culture was fed daily with $1 \mathrm{~mL}$ of baker's yeast $\left(0.02 \mathrm{~g} \mathrm{~L}^{-1}\right)$. After 40 days of experimental period, the samples were prepared for counting and lipid extraction. Counting of density was carried out under a stereo microscope (Leica).

\subsection{Experiment 2: Effect of Salinity onto Harpacticoids under a Hatchery Condition}

Glass beakers of $250 \mathrm{~mL}$ were marked for different salinity of 30ppt and 20ppt. Five replicates beakers were prepared in order to produce large number of copepods. Using a Pasteur pipette, approximately 100 individuals of copepods were transferred from stock culture into each beaker. Filtered sea water and distilled water were added until $150 \mathrm{~mL}$ and until desired salinity were reached. The cultures were maintained at common temperature in the hatchery and at $\mathrm{pH} 7$. Photoperiod was following the natural environmental condition. Each beaker of copepods was fed with $1 \mathrm{~mL}$ of diluted baker's yeast daily in 40 days period before lipid extraction.

\subsection{Experiment 3: Fatty Acids Extraction and Determination from Harpacticoid}

The method used was modified Dole's extraction method [17]. About 200 to 300 individuals of harpacticoid copepods were taken from the cultured copepods and were put into micro-centrifuge tubes. The samples were then freeze dried for 2 days. Meanwhile, extraction solvent was prepared by mixing iso-propanol-n-heptane-phosphoric acid (40:10:1, v/v) and was thoroughly stirred. After that, the freeze dried samples were used for fatty acid analysis. Each sample was transferred from micro-centrifuge tubes into screw-capped test tubes. Then, the samples were mixed with $2.5 \mathrm{~mL}$ of extraction solvent and the tubes were thoroughly vortexed. The tubes were then immersed in a sonicator water bath and were sonicated in 30 seconds intervals for 2 minutes. The samples were then vortexed rigorously and allowed to stay at room temperature for 10 minutes. $1 \mathrm{~mL}$ of heptane and $1.5 \mathrm{~mL}$ of distilled water were added and the tubes were thoroughly vortexed and sonicated again for 1 minute. Tubes were centrifuged at $1,000 \mathrm{rpm}$ for 10 minutes at $4^{\circ} \mathrm{C}$. $1.5 \mathrm{~mL}$ aliquot of the top layer was transferred carefully using micropipette to another test tube and dried under a stream of nitrogen using nitrogen generator leaving lipid sample in it.

Methylation method is carried out by acid methylation following Ichihara and Fukubayashi [18]. $9.7 \mathrm{~mL}$ of $35 \% \mathrm{HCl}$ was diluted with $41.5 \mathrm{~mL}$ of methanol to make $50 \mathrm{~mL}$ of $8 \% \mathrm{HCl}$ also known as $\mathrm{HCl}$ methanol reagent. The lipid samples were dissolved in $0.2 \mathrm{~mL}$ of toluene. Into the lipid solution, $1.5 \mathrm{~mL}$ 
of methanol and $0.3 \mathrm{~mL}$ of the $8 \% \mathrm{HCl}$ solution were added respectively. The test tube was vortexed and was heated at $95^{\circ} \mathrm{C}$ for 1 hour in water bath. After cooling to room temperature, $1 \mathrm{~mL}$ of hexane and $1 \mathrm{~mL}$ of water were added into the samples. The tubes were vortexed, and then the hexane layer was transferred into another tubes followed by drying under stream of nitrogen. The lipid left was diluted with $100 \mu \mathrm{L}$ of hexane, transferred into vials. The concentrated sample was then injected into Gas chromatography-mass spectrometry (GC-MS) to read the spectra using caprylic acid $\left(\mathrm{CH}_{3}\left(\mathrm{CH}_{2}\right)_{6}(\mathrm{COOH})\right.$ as an internal standard.

Percentage of fatty acid detected in each treatment was expressed in Mean \pm SD. Analysis of Variance (ANOVA) test was used to check the difference in FAs percentage between treatments. The names of fatty acid displayed by the library were recorded. Area under the peak of chromatogram was used to calculate the percentage of each fatty acid. The percentage is used to determine the levels of fatty acids in copepod samples.

\subsection{Statistical Analysis}

Data analysis was done using a software IBM SPSS Statistics 20 and Microsoft Office Excel 2013. Data were tested for their mean in Microsoft Office Excel 2013. Using the IBM SPSS Statistics 20, normality test was perform using Shapiro Wilk Test, the variance of homogeneity was tested by using Levene's Test, and significant difference (P-value) by using Wilcoxon-Mann-Whitney Test.

\section{$3 \quad$ Results}

\subsection{Population Density of $A$. neglectus under Laboratory Condition}

The population density of $A$. neglectus was calculated by observing and counting all the living individuals present in each culture. The mean number and standard deviation for each treatment of different salinity and temperature was calculated, and the results were illustrated in Figure 1.The $A$. neglectus samples were unable to survive in 5 ppt cultures.

There was a statistically significant effect $(p<0.05)$ of salinity on the mean number of copepod density $(p=0.000369)$. However, there was no significant effect $(p>0.05)$ of temperature on the mean number of copepod density $(p=0.391489)$. The two-way ANOVA results also indicated that there is no significant interaction $(p>0.05)$ between salinity and temperature $(p=0.699673)$. Since there was no significant effect of the chosen temperatures to copepod's density, the lipid analysis was carried out using those cultured under the ambient temperature.

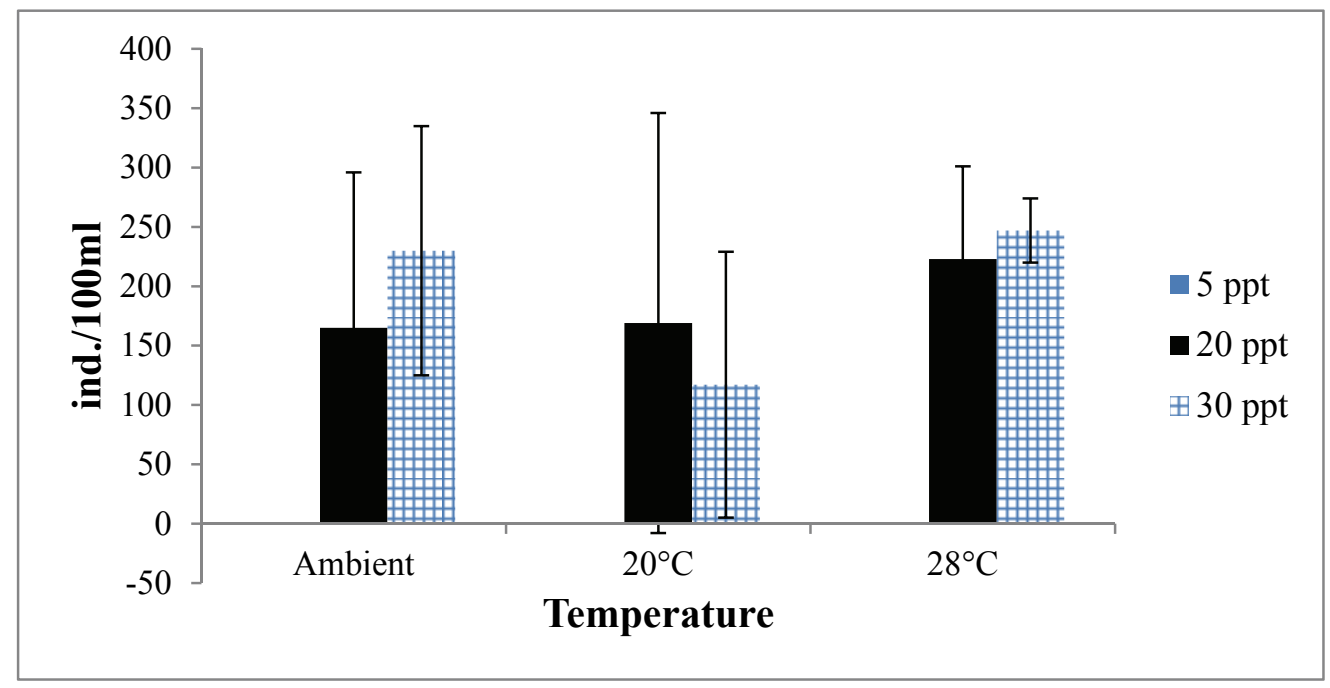

Figure 1. Mean number of A. neglectus under the influence of salinity and temperature in laboratory condition. 


\subsection{Fatty Acids Composition in A. neglectus for 20ppt and 30ppt Salinity at Ambient Temperature in the Laboratory}

The percentage of fatty acid composition in A. neglectus samples were summarized and listed in Table 1 . Lipid numbers are written in the form of $C: D$, where $C$ is the number of carbon atoms present in the fatty acid and $D$ is the number of double bonds present in the fatty acid. Fatty acids composition in $A$. neglectus copepods were characterized into saturated fatty acid (SFA), monounsaturated fatty acid (MUFA), omega-3 polyunsaturated fatty acid (n-3 PUFA) and omega-6 polyunsaturated fatty acid (n-6 PUFA) to determine the total fatty acids percentage. The high polyunsaturated fatty acids (HUFA), arachidonic acid was only found in 30ppt treatment, while eicosapentaenoic acid occurred in high percentage in 20ppt treatment. Linoleic acid was 50\% higher in 30ppt than the 20ppt treatment. Nonetheless, in overall, there is no significant effect of salinity on the percentage of fatty acids in harpacticoid cultured in the laboratory (Table 2).

Table 1. The list of fatty acid composition in the lipid extract of A. neglectus for both 20 ppt and 30 ppt salinity at ambient temperature in the laboratory

\begin{tabular}{cccc}
\hline \multirow{2}{*}{ Types of Fatty Acid } & \multirow{2}{*}{ Lipid Numbers } & \multicolumn{2}{c}{ Percentage (\%) } \\
\cline { 3 - 4 } & & $20 \mathrm{ppt}$ & $30 \mathrm{ppt}$ \\
\hline Myristic acid & $14: 0$ & 8.19 & 7.29 \\
Myristoleic acid & $14: 1$ & 6.54 & 3.89 \\
Palmitic acid & $16: 0$ & 27.82 & - \\
Linoleic acid & $18: 2$ & 15.69 & 33.93 \\
Oleic acid & $18: 1$ & 0.33 & 14.68 \\
Arachidic acid & $20: 0$ & 1.35 & 11.38 \\
Arachidonic acid (AA) & $20: 4$ & - & 4.98 \\
Palmitoleic acid & $16: 1$ & 9.2 & 14.05 \\
Eicosadienoic acid & $20: 2$ & 14.73 & 7.46 \\
Eicosapentaenoic acid (EPA) & $20: 5$ & 16.14 & 2.33 \\
\hline
\end{tabular}

Table 2. Statistical analysis for total fatty acid percentage in the lipid extract of A. neglectus for both 20 ppt and $30 \mathrm{ppt}$ salinity at ambient temperature in the laboratory

\begin{tabular}{lccc}
\hline \multicolumn{1}{c}{ Types of Fatty Acid } & Significance & \multicolumn{2}{c}{ Mean Percentage (\%) \pm SD } \\
\cline { 3 - 4 } & & $20 \mathrm{ppt}$ & $30 \mathrm{ppt}$ \\
\hline Saturated Fatty Acid (SFA) & N.S. & $37.36 \pm 6.93$ & $18.67 \pm 1.51$ \\
Monounsaturated Fatty Acid (MUFA) & N.S. & $16.07 \pm 2.29$ & $10.87 \pm 3.17$ \\
Total Omega Polyunsaturated Fatty Acid (PUFA) & N.S. & $46.56 \pm 0.36$ & $48.70 \pm 7.67$ \\
Omega-3 Polyunsaturated Fatty Acid (n-3 PUFA) & N.S. & $16.14 \pm 0.30$ & $12.33 \pm 2.21$ \\
Omega-6 Polyunsaturated Fatty Acid (n-6 PUFA) & N.S. & $30.42 \pm 0.34$ & $46.37 \pm 8.40$ \\
\hline
\end{tabular}

N.S. $=$ No significance, ${ }^{*}=p<0.05$ and ${ }^{* *}=p<0.01$

\subsection{Fatty Acids Composition in A. neglectus for 20ppt and 30ppt Salinity at Ambient Temperature in the Hatchery}

Table 3. Mean percentage composition of essential fatty acids detected in harpacticoid copepods (A. neglectus) treated with two different salinities in hatchery condition.

\begin{tabular}{|c|c|c|c|c|c|c|}
\hline \multirow{2}{*}{ No. } & \multirow{2}{*}{ Trivial Name } & \multirow{2}{*}{ Structure Name (Essential Fatty Acid) } & \multirow{2}{*}{$\begin{array}{l}\text { Molecular } \\
\text { Formula }\end{array}$} & \multicolumn{2}{|c|}{ Salinity } & \multirow{2}{*}{ P-value } \\
\hline & & & & $30 \mathrm{ppt}$ & $20 \mathrm{ppt}$ & \\
\hline 1 & Arachidonic acid & 5,8,11,14-eicosatetranoic acid, (all-Z) & $\mathrm{C}_{20} \mathrm{H}_{32} \mathrm{O}_{2}$ & $0.04 \pm 0.06$ & - & 0.317 \\
\hline 2 & Timnodonic acid & cis-5,8,11,14,17-eicosapentaenoic acid & $\mathrm{C}_{20} \mathrm{H}_{30} \mathrm{O}_{2}$ & $0.01 \pm 0.02$ & - & 0.317 \\
\hline
\end{tabular}




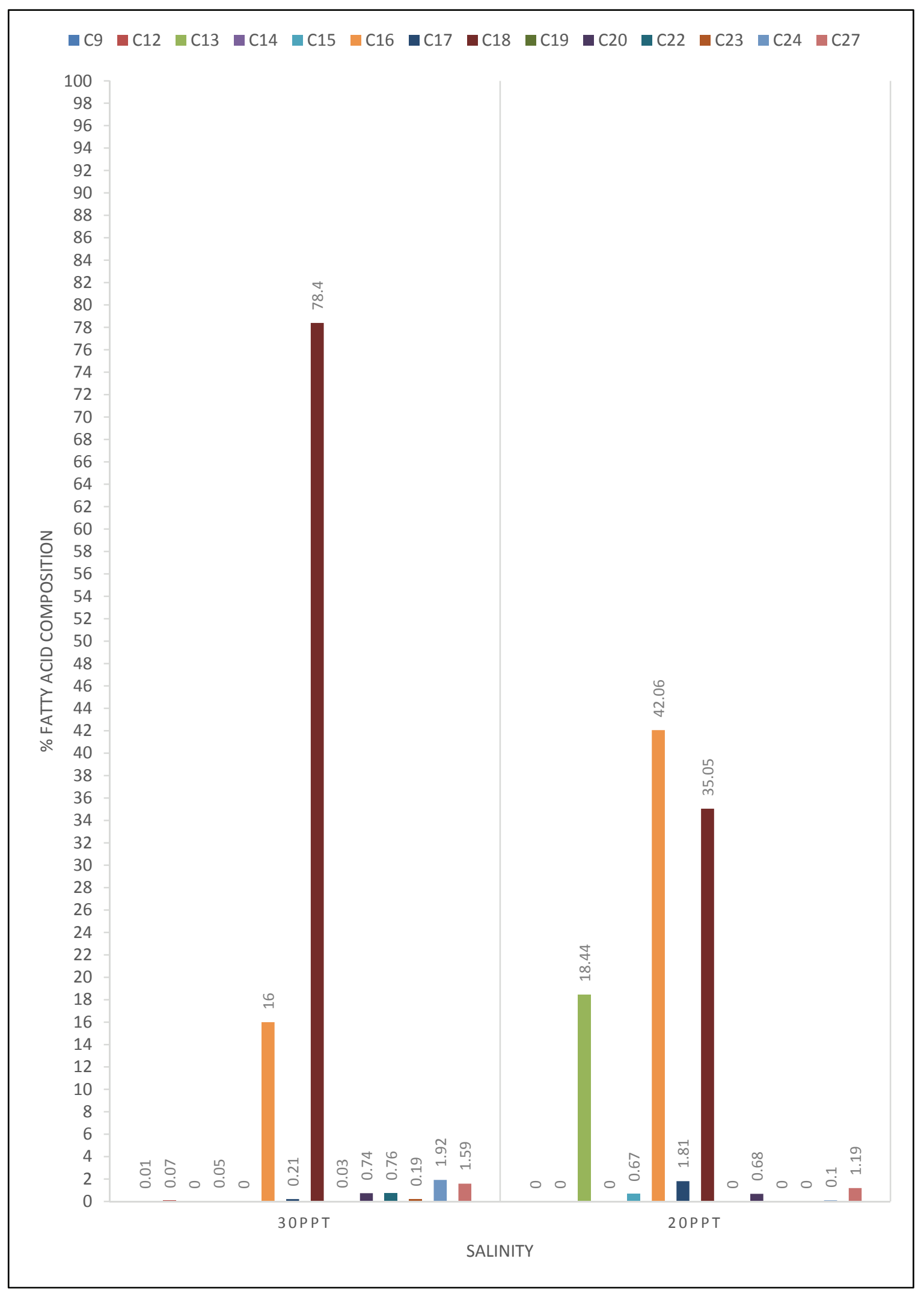

Figure 2. Comparison of percentage fatty acid composition (\%) in A.neglectus. cultured in two different salinities under hatchery condition 
EFA presented in a small amount in the harpacticoid cultured under hatchery condition (Table 3). Two EFAs were detected in this study but with very low concentration (0.01-0.04\%) which is lower than the percentage found under the laboratory culture. Both of them which are arachidonic acid and timnodonic acid and they were detected only in salinity 30ppt under the hatchery condition.

There were more fatty acids detected in the samples treated with salinity 30ppt compared to 20ppt (Figure 2). The significant difference between treatments was observed for the fatty acid composition. It was observed that there were 3nEFAs with significantly varying concentration $(\mathrm{p}<0.05)$; Azelaic acid, Erucic acid, Linodelaic acid (2, 5-octadecadiynoic acid). Other fatty acids were dispersed in different treatments of varying percentages. The expression of $\mathrm{C}_{18}$ in salinity 30ppt showed highest composition percentage with more than $60 \%$ followed by $\mathrm{C}_{16}$ with approximately $20 \%$ while others were recorded with less than $2 \%$. In contrary, the highest percentage fatty acid compositions in salinity 20ppt were $\mathrm{C}_{16}$ followed by $\mathrm{C}_{18}$ with approximately $40 \%$ and $30 \%$ respectively. Others fatty acids were recorded with less than $2 \%$ of fatty acid composition except for $\mathrm{C}_{13}$ with percentage of approximately $20 \%$.

\section{Discussion}

There have been several reports that indicate the capability of marine copepods to survive on a low salinity such as 5ppt, but on the condition that they were acclimatized properly [19][20]. In contrary, the effectiveness of culture condition of higher salinity regime where a harpacticoid copepod, Amphiascoides atopus is found to grow best in salinity range of 25 to $35 \mathrm{ppt}$ was reported [21]. A tropical harpacticoid Nitocra affinis showed the maximum growth in $35 \mathrm{ppt}$ compared to lower salinity [22]. The insignificant differences found in the density when cultured in 20ppt or 30ppt could indicate the optimal salinity for the harpacticoids to grow. A harpacticoid, Pararobertsonia sp., cultured in its optimal salinity and temperature underwent only minimal amount of stress, leading to a higher expression of fatty acids [3].

It was reported that organisms living in a high salinity environment are likely to increase their PUFA content in order to raise membrane fluidity at high salt concentrations [23]. Both cultured in 20 ppt and 30 ppt salinity contained high amount of PUFAs, which can be attributed to A. neglectus adapting in a high salinity environment. EFAs are crucial in stabilizing a healthy ecosystem and are primary source of natural availability of EFA [24]. Other fatty acids also play important rule, such as those in the exoskeleton which could give the intra-specific recognition in Artemia species [25]. The low concentration of several FA found in this study could possibly relate to the diet, in this study all harpacticoids were having yeast as their diet which is known for the low nutrient content if compared to microalgal diet [26].

Photoperiod has shown its effect on fatty acid content [27] and also marine prey [28]. In the hatchery condition lighting was not control and the cultures were exposed more to natural photoperiod. This condition might play a role in managing the expression of fatty acids in the copepod [29]. The natural light exposure during daytime could be different depending on the daily tropical weather condition. The effect could be different from the constant light condition and this might affect the reproduction as well [30]. Further investigation on photoperiod effect would give the answer.

\section{Conclusion}

A harpacticoid copepod A. neglectus was successfully cultured under a laboratory and hatchery condition where salinity was maintained at the salinity of 20 and $30 \mathrm{ppt}, \mathrm{pH} 7$ and ambient temperature in the laboratory and hatchery. Exposure to the culture condition in the laboratory with salinity 20 and $30 \mathrm{ppt}$ gave no significant difference $(\mathrm{p}>0.05)$ in the composition of fatty acids. Both treatment of 20 ppt and 30 ppt salinity contain a very high yet almost equal amount of PUFAs, which can be attributed to A. neglectus adapting in a high salinity environment. Nonetheless, the composition was significantly higher for the copepods cultured at the same salinities under hatchery condition. The significant difference between treatments was observed for the fatty acid composition. Hatchery condition with more natural photoperiod might play a role in managing the expression of fatty acids in the copepod. 
Acknowledgement. The authors acknowledged the financial support from IIUM RIGS grant number RIGS 16-315-0479.

\section{References}

1. J.G. Støttrup and N.H. Norsker, "Production and use of copepods in marine fish larviculture," Aquaculture, vol. 155, no. 4, pp. 231-247,1997.

2. A.D. McKinnon, S.Duggan, P.D.Nochols, M.A. Rimmer, G. Semmens and B. Robino, "The potential of tropical paracalanid copepods as live feeds in aquaculture", Aquaculture, vol. 223, pp. 8-106, 2003.

3. K. Zaleha, A. John, H. Asgnari, Al-Aama, and M.A. Fuad, "Fatty acid profiling of benthic harpacticoid (Pararobertsonia sp.) exposed to environmental stresses," Malaysia Applied Biology, vol.43, no. 1, pp. 31-40, 2014.

4. M. Dias, A. Silva, H. Cabral and C. Vinagre, "Diet of marine fish larvae and juveniles that use rocky intertidal pools at the Portuguese Coast," Journal of Applied Ichthyology, vol. 30, no. 5, pp. 970-977. 2014.

5. T. Mascart, G. Lepoint, S. Deschoemaeker, M. Binard, F. Remy and M. De Troch, "Seasonal variability of meiofauna, especially harpacticoid copepods,in Posidonia oceanica macrophytodetritus accumulations," Journal of Sea Research, vol. 95, pp.149-160, 2015.

6. J.M. Gee, "An Ecological and Economic Review of Meiofauna as Food for Fish," Zoological Journal of the Linnean Society, vol.96, pp. 243-261, 1989

7. S.Shimode and Y. Shirayama, "Diel Vertical Migration and Life Strategies of Two Phytal-dwelling Harpacticoids, Ambunguipes rufocincta and Eudactylopds spectabilis," Plankton and Benthos Research, vol.1, no. 1, pp. 42-53, 2006.

8. Zaleha Kassim, Muhammad Solleh Majid, Nur Yahdiyani Mat Alwi, Hazwani Hanim Hasnan. Diet Preferences of Small Fishes at Setiu Lagoon, Malaysia. Ecology and Sustainable Development, vol. 1, no.1, pp. 9-17. 2018.

9. C.J. Cutts, "Culture of harpacticoid copepods: Potential as live feed for rearing marine fish," Advances in Marine Biology, vol. 44, pp. 295-316, 2003.

10. L.C.M .Lima, D.M.A.F. Navarro and L. P. Souza-Santos, "Effect of diet on the fatty acid composition of the copepod Tisbe Biminiensis," Journal of Crustacean Biology, vol. 33, no.3, pp. 372-381, 2013.

11. E. Werbrouck, D.V. Gansbeke, A. Vanreusel and M.D. Troch, "Temperature Affects the Use of Storage Fatty Acids as Energy Source in a Benthic Copepod (Platychelipus littoralis, Harpacticoida)," PLoS ONE, vol.11, no.3, pp. 1-16, 2016.

12. S.H. Lee, M.C. Lee, J. Puthumana, J.C. Park, S. Kang, J. Han, K.H. Shin, H.G. Park, A.S. Om and J.S. Lee, "Effects of temperature on growth and fatty acid synthesis in the cyclopoid copepod Paracyclopina nana," Fisheries Science, vol.83, no.5, pp. 725-734, 2017.

13. J. Garzke, T. Hansen, S.M.H. Ismar and U. Sommer, "Combined Effects of Ocean Warming and Acidification on Copepod Abundance, Body Size and Fatty Acid Content" PLoS ONE, vol. 11, no. 5, pp.1-22, 2016.

14. C. Ladhar, H. Ayadi, F. Denis, E.Tastard and I. Sellami, "The effect of environmental factors on the fatty acid composition of copepods and Artemia in the Sfax solar saltern (Tunisia)" Biochemical Systematics and Ecology, vol. 56, pp. 237-245, 2014.

15. S. Bollmohr, R. Schulz, and T. Hahn, "Interactive effect of salinity decrease, salinity adaptation, and chlorpyfiros exposure on an estuarine harpacticoid copepod, Mesochra parva, in South Africa," Ecotoxicology and Environmental Safety, vol. 72, no. 3, pp.756-64, 2009.

16. D.A.Nanton and J.D. Castell, "The effects of dietary fatty acids on the fatty acid composition of the harpacticoid copepod, Tisbe sp., for use as a live food for marine fish larvae," Aquaculture, vol. 295, no.1-2, pp.120-125, 1998.

17. M. Püttmann, H. Krug, E.V. Ochsentein and R. Kattermann, "Fast HPLC determination of serum free fatty acids in the picomole range" Clinical Chemistry, vol.39, pp. 825-832, 1993.

18. K. Ichihara and Y. Fukubayashi, "Preparation of fatty acid methyl esters for gas-liquid chromatography," Journal of Lipid Research, vol. 51, no.3, pp.635-640, 2010.

19. R.M. Damgaard and J. Davenport, "Salinity tolerance, salinity preference and temperature tolerance in the high-shore harpacticoid copepod Tigriopus brevicornis," Marine Biology, vol.118, no.3, pp. 443-449, 1994. 
20. K. Zaleha and I. Busra, "Culture of harpacticoid copepods: understanding the reproduction and effect of environmental factors," in Aquaculture. InTech, 2012, pp. 343-360.

21. B. Sun and J.W. Fleeger, "Sustainable mass culture of Amphiascoides atopus a marine harpacticoid copepod in a recirculating system," Aquaculture, vol.136, pp. 313-321, 1995.

22. H. Matias-Peralta, F.M. Yusoff, M. Shariff and A. Arshad, "Effects of some environmental parameters on the reproduction and development of a tropical marine harpacticoid copepod Nitocra affinis $f$. californica Lang," Marine Pollution Bulletin, vol.51, pp.722-728, 2005.

23. A. Ventosa, A. Oren and Y. Ma, Halophiles and Hypersaline Environments: Current Research and Future Trends. Springer. 2011.

24. M.T. Arts, R.G. Ackman and B.J. Holub, "Essential fatty acids in aquatic ecosystems : A crucial link between diet and human health and evolution," Canadian Journal of Fishery and Aquaculture Science, vol. 58, pp. 122137, 2001.

25. C. Tapia, L. Parra, A. Mutis, G. Gajardo and A. Quiroz, "Fatty acid methyl esters extracted from the cuticular surface of Artemia franciscana (Kellogs, 1906) (Crustacea: Anostraca) increase the swim speed of conspecific males," Gayana, vol. 80, no.2, pp. 154-160, 2016.

26. S. M. Renaud and D.L. Parry, "Microalgae for use in tropical aquaculture II: Effect of salinity on growth, gross chemical composition and fatty acid composition of three species of marine microalgae," Journal of Applied Phycology, vol. 6, no. 3, pp. 347-356, 1994.

27. L.K. Chin and K. Zaleha, "Effect of photoperiod on the cellular fatty acid composition of three tropical marine microalgae," Malaysian Applied Biology, vol. 42, no. 1, pp. 41-49, 2013.

28. S. Kaartvedt, "Photoperiod may constrain the effect of global warming in artic marine system," Journal of Plankton Research, vol. 30, no. 11, pp. 1203-1206, 2008.

29. G. Drillet, S. Frouël, M.H. Sichlau, P.M. Jepson, J.K. Højgaard, A.K. Joarder and B.W. Hansen, "Status and recommendations on marine copepod cultivation for use as live feed," Aquaculture, vol. 315, pp. 155-166, 2011.

30. N. Nogueira, B. Sumares, C.A.P. Andrade and A. Afonso, "The effects of temperature and photoperiod on egg hatching success, egg production and population growth of the calanoid, Acartia grani (Calanoida: Acartiidae)" Aquaculture Research, 49(1): 93-103, 2018. 